\title{
Automated Assembly Technology in Bicycle Production
}

\author{
Fengxu Zhou', a , Yafei He ${ }^{1, b}$ \\ ${ }^{1}$ Shanghai Polytechnic University, School of Intelligent Manufacturing and Control Engineering, \\ 2360 Jinhai Road, Shanghai, China \\ afxzhou@sspu.edu.cn, byfhe@sspu.edu.cn
}

\begin{abstract}
Keywords: Bicycle Assembly Process, Automated Assembly, MES
Abstract. The basic structure of the bicycle was introduced. The assembly process of the bicycle was given. The automatic assembly technology was used to realize the assembly of the key parts of the bicycle. Through the intelligent production management system, MES, the entire assembly process of bicycle information was achieved, which was intelligent and visualization. The accuracy of bicycle assembly was improved. The assembly time was shorted. Using assembly-type AGVs the flexible assembly of the bike might be achieved, which could lay the foundation for the future customization of bikes.
\end{abstract}

\section{Introduction}

As the increase of population and the growing scale of human production, environmental pollution is becoming the biggest threat to human survival. In the daily travel, the bikes are becoming more and more popular because of its low-carbon, environmental protection, auxiliary fitness and other features. Due to the particularity of bicycle parts, the traditional bicycle assembly technology is basically used manual assembly. This assembly model is labor intensity, low production efficiency, not high assembly accuracy, and high production costs. It is difficult to adapt to fierce market competition. In 2013, the German government proposed the "Industrial 4.0" strategy, and officially launched in the Hanover industrial fair. The strategy has been widely recognized proposed by the German scientific research institutions and industrial community since it was proposed. China, as a manufacturing power, plays high attention to the development of intelligent manufacturing. The achievement of bicycle intelligent assembly will not only be in line with the national manufacturing transformation but also seek a new way out for the development of the bicycle manufacturing industry.

At present, the automated assembly technology in the production process has made some achievements. Ružarovský R[1] presented the description of the new conception philosophy, design of the individual units in the system characterized as an intelligent assembly cell, functions principles and expected proceedings in the next phases of the project. Sivia S[2] designed an automation sensory equipment which could provide for automatic monitoring of all automated equipment motions in the first case and in the second important level was important to obtain the information about the status, presence and character of the assembled objects or assembly process. Sebenova I[3] designed a palletizing workplace with industrial robot IRB 120, specifically in the design of the automation equipment which was based on the possibility of the application. Applegate R[4] provided an adapter assembly which included housing for connection with a surgical device and for operative communication with at least one rotatable drive shaft of the surgical device. Liu M, et al.[5] proposed the concept of IoT-enabled intelligent assembly system for mechanical products. Yong-Hua HU et al.[6] presented an intelligent assembly procedure structure together with corresponding syntax processing scheme.

\section{Bicycle Structure and Assembly Process}

Bicycles mainly include the frame, wheels, tires, shifters, seat stay, brakes, saddle, seat posts, cranksets and pedals, et al. as shown in Fig.1. The basic components are indispensable. Among them, the frame is the skeleton of the bicycle, it bears the maximum weight. Other parts are all installed 
directly or indirectly on the frame. Bicycle relies on the body's driving force and cycling skills to drive. The frame is the important structure to bear the driving load and determines whether the comfort and safe to the users. The manufacturing accuracy and the degree of cooperation of the assembly process will directly affect the ride safety, smooth, and springiness.

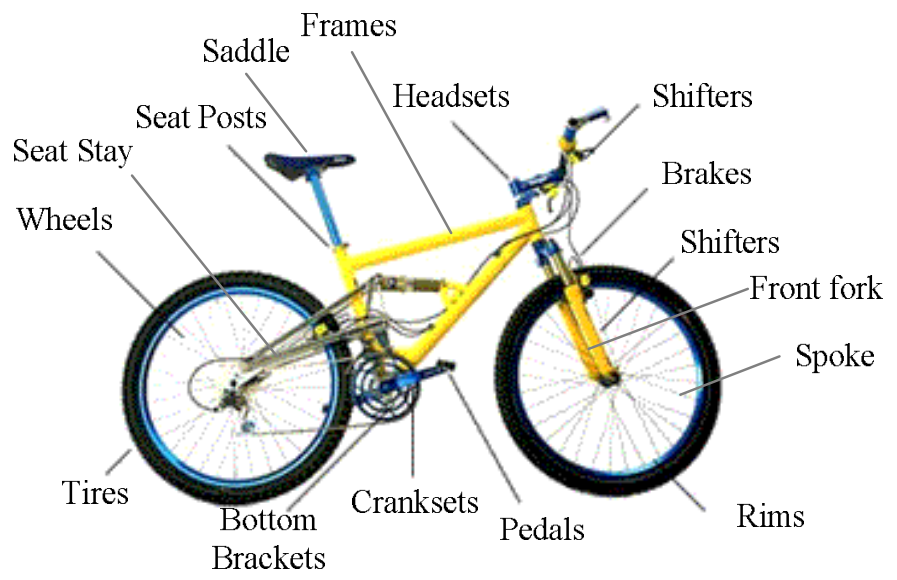

Fig. 1 The basic structure of a bike

Bicycle assembly is mainly divided into parts assembly and vehicle assembly. Vehicle assembly mainly includes front and rear wheels assembly, frame on the line, spindle preload, drive shaft assembly. Component assembly mainly includes variable speed gear installation, and handlebar, seat attachment installation. In all parts of the bicycle, the wheel assembly process is relatively complex, which mainly includes the installation of the spokes, tightening, sealing and turning ring correction and other links. The assembly process of the bicycle is shown in Fig.2.

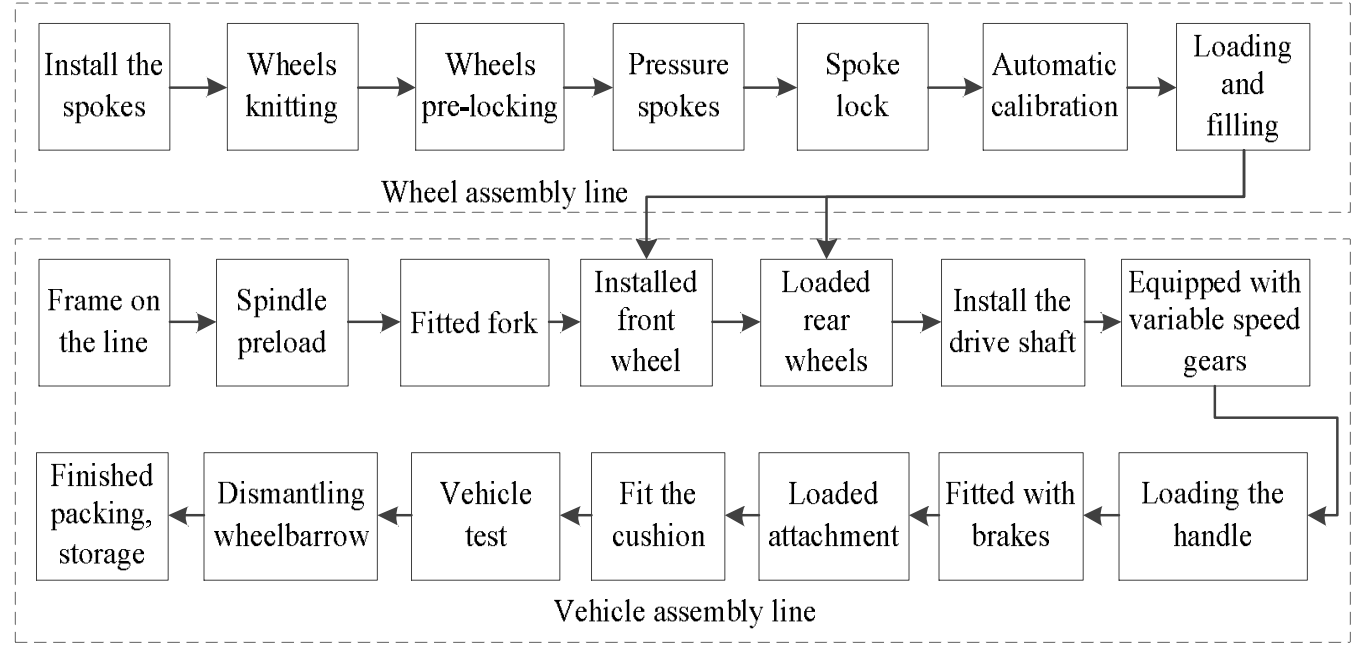

Fig.2 Bicycle Assembly Process

\section{Automated Assembly Technology in Bicycle Assembly Production Line}

Automated assembly technology. Automated assembly technology is inseparable from the automated production management system and robot automated assembly process. Automated production management system is integrated by the ERP system, MES system and SFC system. An information management system is as shown in Figure 3. The system is composed of three-tier structure model. In the process of production process management, the control layer is mainly used to solve the practical problems on the production line. The planning layer is mainly used for the macro process design of the production plan. The executive layer is mainly used for the management of the production process. The control layer mainly solves the practical problems on the production line. The MES system receives and executes the generation plan from the upper ERP system. It is a monitoring and feedback of the ERP plan. The MES can optimize the entire production process of the product through the delivery of the product. When a real-time event occurs in the workshop, MES can respond to, report that. In addition, MES can direct and process them with current accurate data. And then through the PCS production site management and control system on-site, the real-time data can be 
collected, analyzed and controlled to achieve the digital manufacturing process management and to improve the production line production efficiency and product quality.

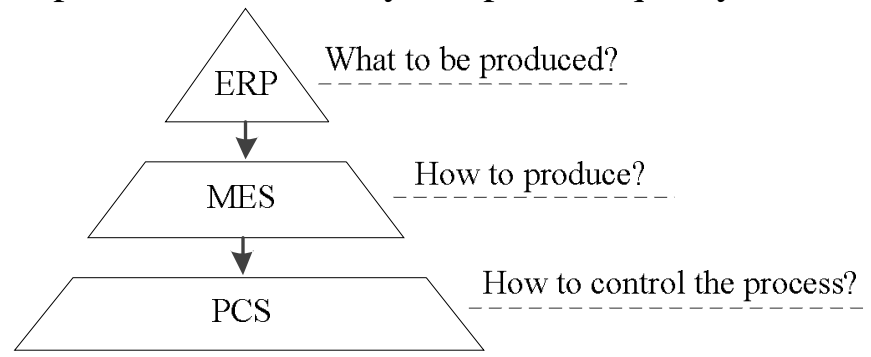

Fig.3 Automated production management system

Manufacturing industry upgrading is emerging in the world. It is the inevitable development of manufacturing industry to achieve human-computer interaction, coordination and cooperation. AGV, as an all-round automated mobile platform, provides an effective solution for automated plant lean distribution and automated manufacturing. AGV has high flexibility, scalability and has a good security barrier system, low cost, efficient logistics. The running routes of AGV can be changed. And it is easier to import new models by using AGV delivery.

Application of Bicycle Automated Assembly Production Line. Bicycle assembly automated production management system, as shown in Figure 4, mainly includes the order management, production operations planning management, basic data management, material management, production management and quality management and other subsystems et al.

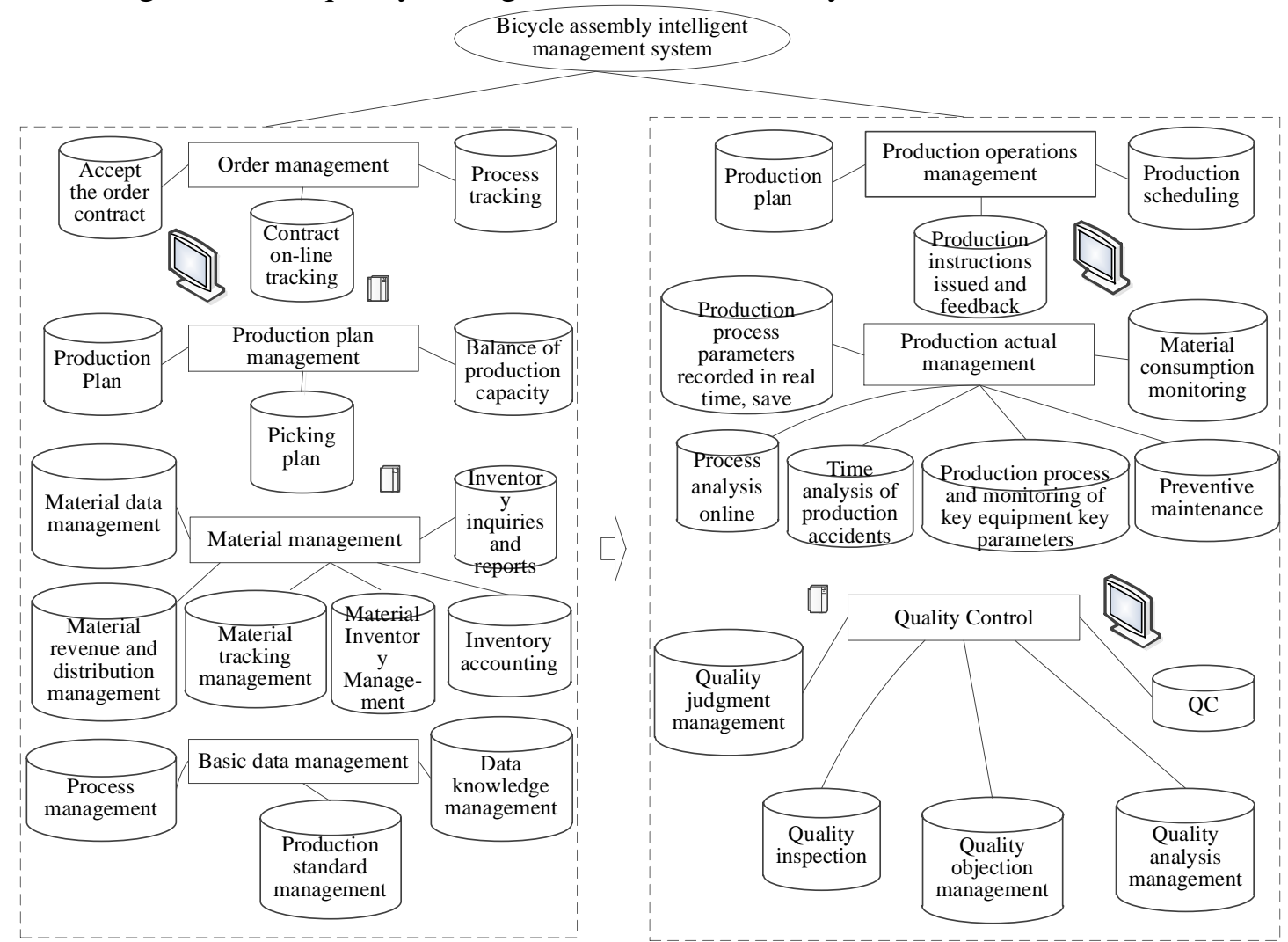

Fig.4 Bicycle assembly automated production management system

MES can optimize the management of the entire bike production process from the order to the completion of the product through information transmission. When real-time events occur in the plant, MES can respond to, report, and direct and prioritize them with current accurate data. This rapid response to state changes allows MES to reduce activity within the enterprise without additional value, effectively guide the production process of the plant, so that it can improve the timely delivery capacity of the factory, improve the material flow performance, but also improve production rate of return. MES system generally includes order management, material management, process management, 
production scheduling, quality control, equipment control and external system PCS integrated interface and ERP integration interface module.

With such a bicycle automatic assembly management system, managers do not have to leave the desk, you can view the production status of the workshop equipment, the system can analyze the entire department equipment, or specify the status of the device, which device is currently in the idle, debugging In the processing or in the shutdown as shown in Figure 5, red on behalf of the equipment downtime, green on behalf of the equipment processing, yellow on behalf of the equipment debugging. In addition, you can display the current processing tasks and operator information for each device. It keeps track of each operator's time, such as start-up, processing, commissioning, downtime or idle time, which helps shop managers really understand how resources are being used and, more importantly, Production links can be improved to reduce unnecessary commissioning time, downtime and idle time.

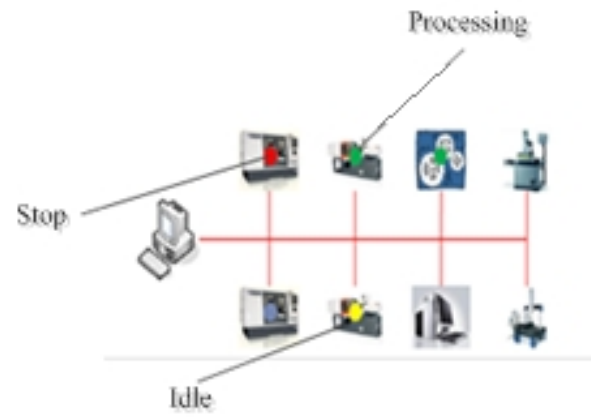

Fig.5 Device status display

AGV Automated Assembly Transport Car for Bicycle Assembly. All-round transport assembly AGV with magnetic navigation, as shown in Figure 6, can have a radius of 1 meter radius, and can be automatically on-line fast charging. For equipped the lifting mechanism, AGV can achieve assembly function. In addition to that, the AGV can also be wireless LAN communication, simple map collision avoidance and scheduling and dynamic tracking function.

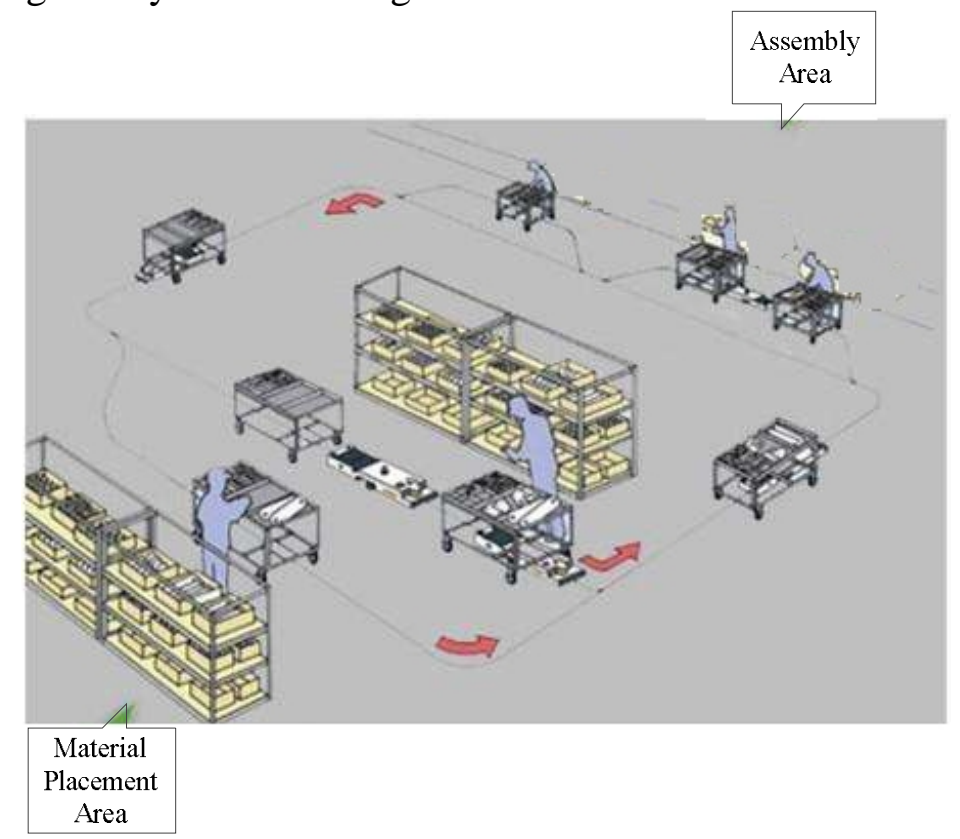

Fig.6 AGV logistics route

The AGV console receives the detection of the body position signal on the catenary and automatically dispatches the AGV which has been loaded with the front fork and the crank set into the lower part of the cable at a predetermined time and captures the cooperation target fixed on the bicycle frame in the predetermined area, To maintain a stable tracking state, and automatically lift the front fork and the crank set to the predetermined position, the manual control lift the work piece to the installation location, by the assembly workers to install fixed bolts, complete the assembly after the end 
of the signal. According to the front fork and the crank set of the installation of the end of the signal or timing signal, AGV automatically fall down the structure, speed out the assembly station, return to the loading station ready fork and crank set, complete a work cycle. When the front fork and the crank set cannot be supplied in time, it should be operated by the catenary emergency stop switch which is set in the assembly station.

\section{Conclusions}

Now, low-carbon life makes riding a bike is no longer just a way of transport or fitness, more people will see it as a life will enjoy the attitude. Personality of the young people want to have one or two turn to their own, unique exclusive bike, personalized custom is the future development trend of the bike. The application of automated assembly technology and intelligent information management system in bicycle assembly process will promote the development of personalized customization of bicycle industry. The assembly type AGV provides favorable conditions for bicycle customization and flexible production.

\section{Acknowledgements}

This work was financially supported by the Shanghai Polytechnic University Foundation (A01GY17EX49).

\section{References}

[1] Ružarovský R, Danišová N, Velîšek K. Application of Assembly System Partial Units for the Development of Intelligent Assembly Cell[J]. Applied Mechanics \& Materials, 2013, 309(6):3-11.

[2] Sivia S, Krajcova K, Karol V. Sensors in the Subsystems of Intelligent Assembly Cell[J]. Applied Mechanics \& Materials, 2012, 220-223(3):1825-1828.

[3] Sebenova I, Velisek A. THE AUTOMATION EQUIPMENT IN THE PALLETIZING WORKPLACE IN THE INTELLIGENT ASSEMBLY CELL[J]. Annals of Daaam \& Proceedings, 2012.

[4] Applegate R. Intelligent adapter assembly for use with an electromechanical surgical system[J]. 2014.

[5] Liu M, Ma J, Lin L, et al. Intelligent assembly system for mechanical products and key technology based on internet of things[J]. Journal of Intelligent Manufacturing, 2017, 28:1-29.

[6] Yong-Hua HU, Chen SM, Qiu YQ, et al. Syntax Processing Scheme for Intelligent Assembly Procedures of VLIW DSP[J]. Journal of Shaoyang University, 2016. 